\title{
Organic Chemistry for First Year Medical Students: Addressing the 'Grand Public'
}

\author{
Stefan Matile*
}

\begin{abstract}
Experiences from 20 years of teaching organic chemistry at the Medical School of the University of Geneva are recollected. Emphasis is on the question how to address a large audience without particular passion for chemistry. The key lesson learned is to offer a substantial justification for every topic right at the beginning, before the basics are covered. For instance, the course opens with vancomycin resistance, achieved by changing one functional group, even one atom into another, and introductory topics are then developed literally on the structure of a beautifully complex natural product (relation of molecules, functional groups and atoms, introduction of functional groups, the octet rule, hybridization, later on also peptide chemistry, stereochemistry, etc.). Tamiflu is launched right afterwards as a possible justification why medical students should learn reaction mechanisms, long before the concerned reaction, the transformation of an acetal into a hemiacetal, is discussed. Not all classical teaching topics are compatible with such 'relevance-triggered teaching' (nomenclature certainly not, nor halogenoalkanes, aromatic substitutions, alkynes, most of alkenes, spectroscopy, etc.). Other topics deserve more attention, like the more complex cyclic structures of sugars and steroids in the structural part and carbonyl chemistry, including catalysis, as the center of the reactivity part of the course. Difficult to measure, such 'relevance-triggered' course restructuring, inconceivable from a classical educational point of view, has been overall surprisingly well received, although definitely not by all students.
\end{abstract}

Keywords: Chemistry teaching $\cdot$ Tertiary level

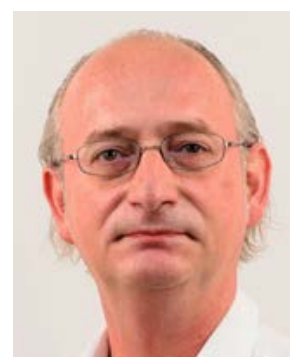

Stefan Matile is a Full Professor in the Department of Organic Chemistry at the University of Geneva and a founding member of the National Centre of Competence in Research (NCCR) Chemical Biology and the NCCR Molecular Systems Engineering. In 2010, he became an ERC Advanced Investigator. Educated at the University of Zurich (PhD, with Wolf Woggon) and Columbia University in New York (postdoc, with Koji Nakanishi), he started his independent academic career as an Assistant Professor at Georgetown University, Washington DC, before moving to Geneva. He likes supramolecular systems in action, at work, to equip them with unorthodox interactions, expecting that only new ways to get in touch would yield the privileged scaffolds needed to ultimately tackle persistent challenges. Current emphasis is on catalysis with anion- $\pi$ interactions, chalcogen and pnictogen bonds, extreme sulfur chemistry to find new ways to enter into cells (and hinder viruses to do the same), and mechanochemical fluorescent probes to image physical forces in biology.

It will now be 20 years that I am teaching organic chemistry to first year medical students in Geneva. When I was asked to talk about my experience at the Fall or Spring Meeting of the Swiss Chemical Society and then also to follow up with a written article, I hesitated. I always simply focused on doing my service as well as I could and never considered these efforts worth publishing. Being finally talked into writing this recollection, I would like to apologize in advance: All eventual misplaced remarks, all eventual errors respond to 'field experience' and are made with the best intentions; they certainly are not meant as any form of criticism to others that are much more knowledgeable on educational aspects

${ }^{\star}$ Correspondence: Prof. S. Matile. E-mail: Stefan.Matile@unige.ch

Department of Organic Chemistry, University of Geneva, Geneva, Switzerland. than I am. I would of course be truly delighted if what follows would produce useful feedback and possibly stimulate the writing of organic chemistry textbooks, perhaps even for the high-school level, which I find very important.

I found teaching organic chemistry to first year medical students always most important because only the experts in a given discipline can possibly provide what all our students deserve, that is top standards together with contagious enthusiasm. However, I found it also fascinating because teaching to first year medical students presents also a quite unique opportunity to address what in French is the 'grand public'. In Geneva, no admission exams restrict access to the Medical School, which can result in more than 700 students in the first year. This large audience is obviously not there for chemistry and often marked by negative prejudices. Over the years, the numbers will add up and students will spread out in the local society, far beyond medicine. Hopefully, they will remember chemistry not with true passion but an appreciation for a science that is: central, creative and useful - the three magic words used in the course, and with the 'grand public' (see below, Fig. 1)

Teaching organic chemistry to first year medical students in Geneva is complicated by 1) the very different levels of chemistry knowledge of the entering students, from beginner to quite advanced, 2) the limited time available and 3) the advanced level most relevant organic chemistry in medicine asks for. The three challenges all together might feel like Catch-22, mission impossible. Following a classical teaching approach, time is already up after covering nomenclature and introducing basic reactivity with the halogenoalkanes. In the first curriculum revision I attended after my arrival in Geneva, around 2005, it was thus suggested that the sciences, including the classical chemistry textbook education, are anyway less important for medical students and have to be cut, if not completely removed. Looking at standard introductory organic chemistry with the other members of the curriculum revision committee, I had to agree, at least partially, with regard to content, but not at all with the cuts. It was easy to find examples 


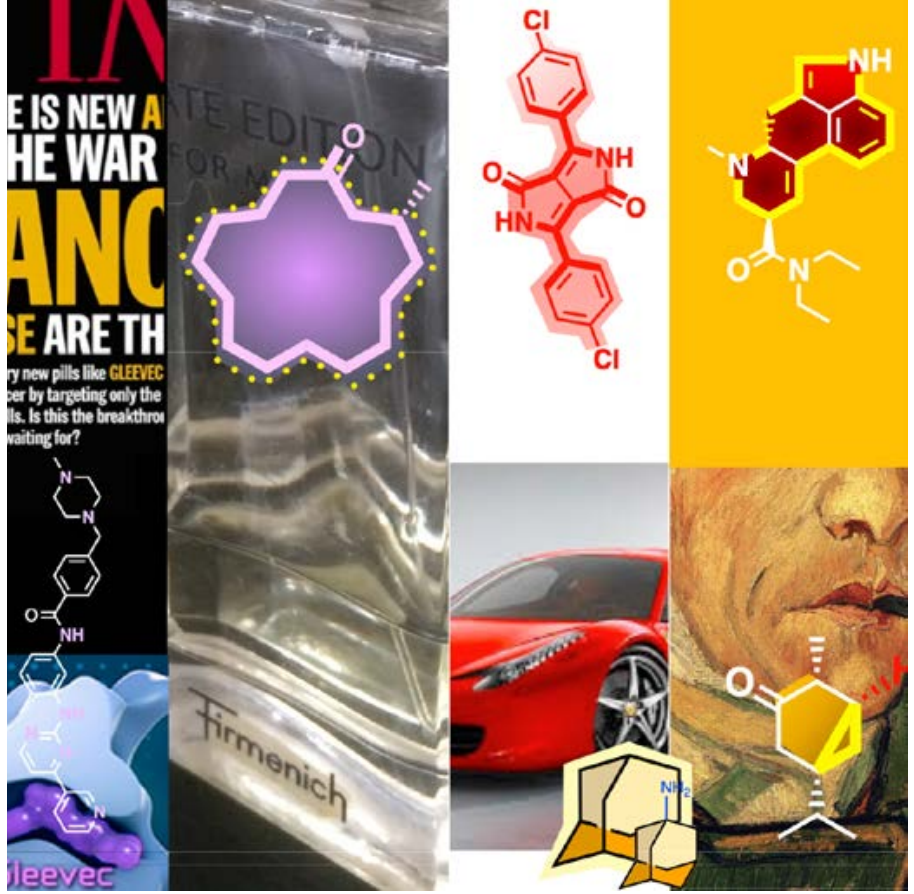

Fig. 1. A collage of molecular masterpieces related to Switzerland, not only pharmaceuticals like gleevec but also muscone, Ferrari red, adamantane and antivirals, $\alpha$-thujone or LSD (from left to right). Adapted from course material.

why organic chemistry as such would be most relevant for medical students and similarly interesting for the 'grand public'. Together we thus started to collect the topics that deserved to be taught, and I was asked to assemble them into a new course. I hesitated to follow this request because it was running so clearly against the basic principles of organic chemistry education.

To my surprise, the new course, although clearly more demanding, was very well accepted (although definitely not by all students, but this is obviously not possible with any format). I was impressed by this response. It suggested that medical students can appreciate and are open to invest into organic chemistry as long as every topic covered is convincingly justified. In my experience, the critical point is that this justification comes first, not last. We are all familiar with book chapters closing with colorful anecdotes that what we just learned also explains this and that in biology and medicine. In the course we constructed in Geneva, every topic starts with a serious justification to first convince the students and then to serve as a basis to teach the basic organic chemistry needed to understand it (Fig. 2). A bit like teaching in reverse. From complex to basic, rather than from basic to complex. I was thinking of names that would best describe this critical point, justification first, content second: 'Relevance-triggered teaching' could work, suggestions are welcome, examples will follow. Relevancetriggered teaching also conveniently does not solve but alleviate the problem of the different levels of the entering students. More advanced students will not be bored by contemplating the justifications, beginners can focus more on the basics. The fundamental principles are introduced with the French translation of the short version of the McMurry-Simanek textbook ${ }^{[1]}$ as a backup and do not need more discussion here. Their selection, order and particularly their interfacing with 'relevance-triggers' - the serious justifications that come first - will be illustrated briefly in the following with some examples.

I find the introduction most important to win over as much of the audience as possible right from the beginning. 'Central, creative, useful' comes first. Chemistry is the central science because chemistry "...travaille sur des molécules...", as beautifully put by a journalist from Le Temps, ${ }^{[2]}$ and many solutions in science and medicine are found on the molecular level. Creative because no other discipline creates new matter as explicitly as chemistry, putting atoms in place like sculptors, illustrated with one of these legendary photos of Alberto Giacometti at work in Geneva. ${ }^{[3]}$ Finally, chemistry is useful because the thus created molecular sculptures are not simply useful but truly essential for our society. In Switzerland, they account for much of the quality of life, $>1 / 3$ of our GDP, probably unique worldwide, mysteriously underappreciated locally. This importance of Swiss chemistry is visualized with a collage, stating that it is not just pharmaceuticals, exemplified with gleevec on the cover of TIME magazine (Fig. 1). ${ }^{[4.5]}$ No, there are also fragrances, muscone for example, ${ }^{[6,7]}$ our seigneurs des anneaux moléculaires, with the Firmenich Private Edition presented live in the course to admire this chimie genevoise irrésistible. Other Swiss 'masterpieces' include Ferrari
Fig. 2. Relevance-triggered teaching of organic chemistry to medicine students: Vancomycin and the origin of resistance are introduced first to justify that a basic understanding of functional groups and atoms is needed to understand the change from an amide to an ester and a nitrogen to an oxygen, respectively. The antibiotics structure is then used right away to introduce the drawing of carbons, octet rule, hybridization, functional groups, and so on (screen-shot collage of course material).
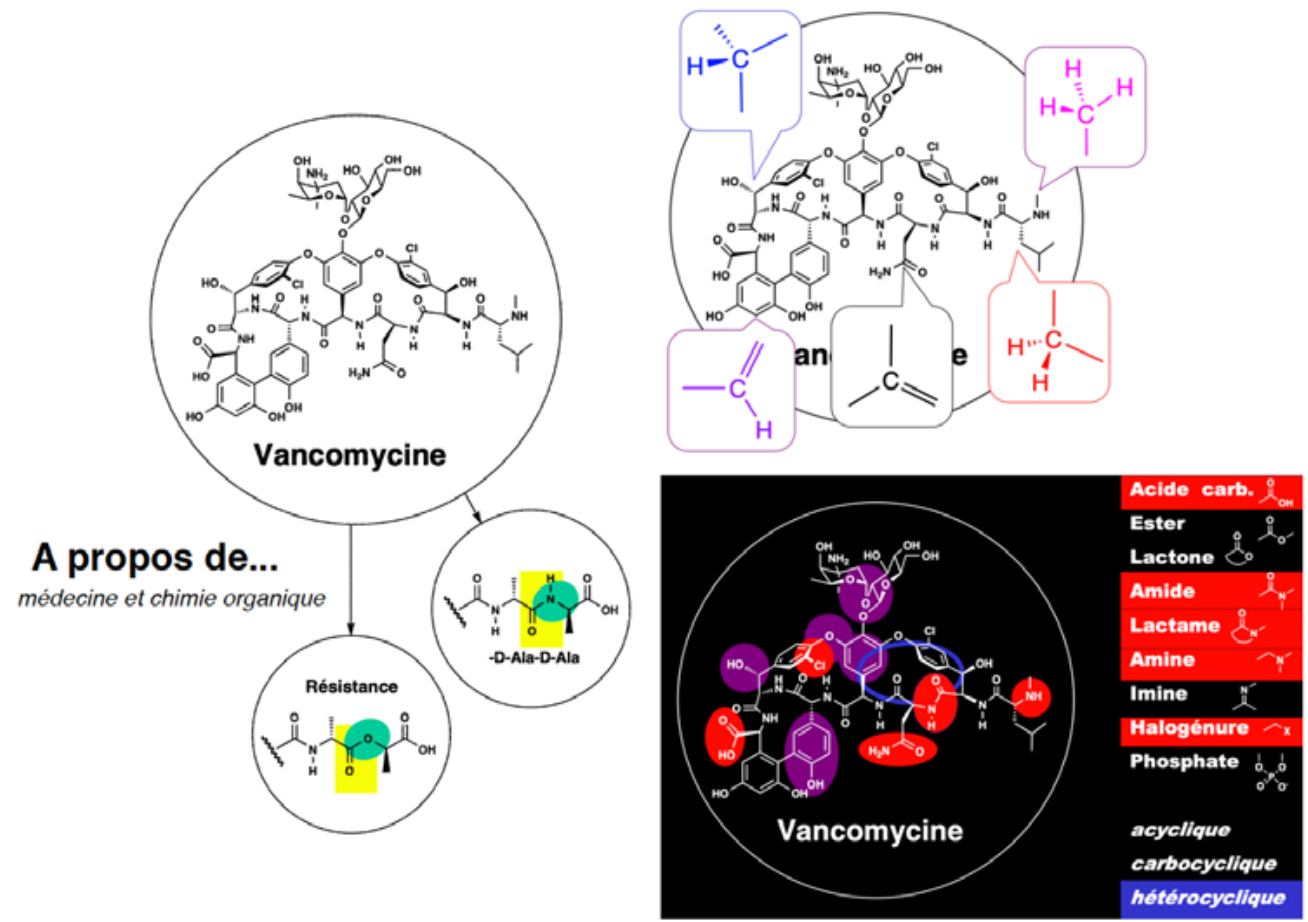


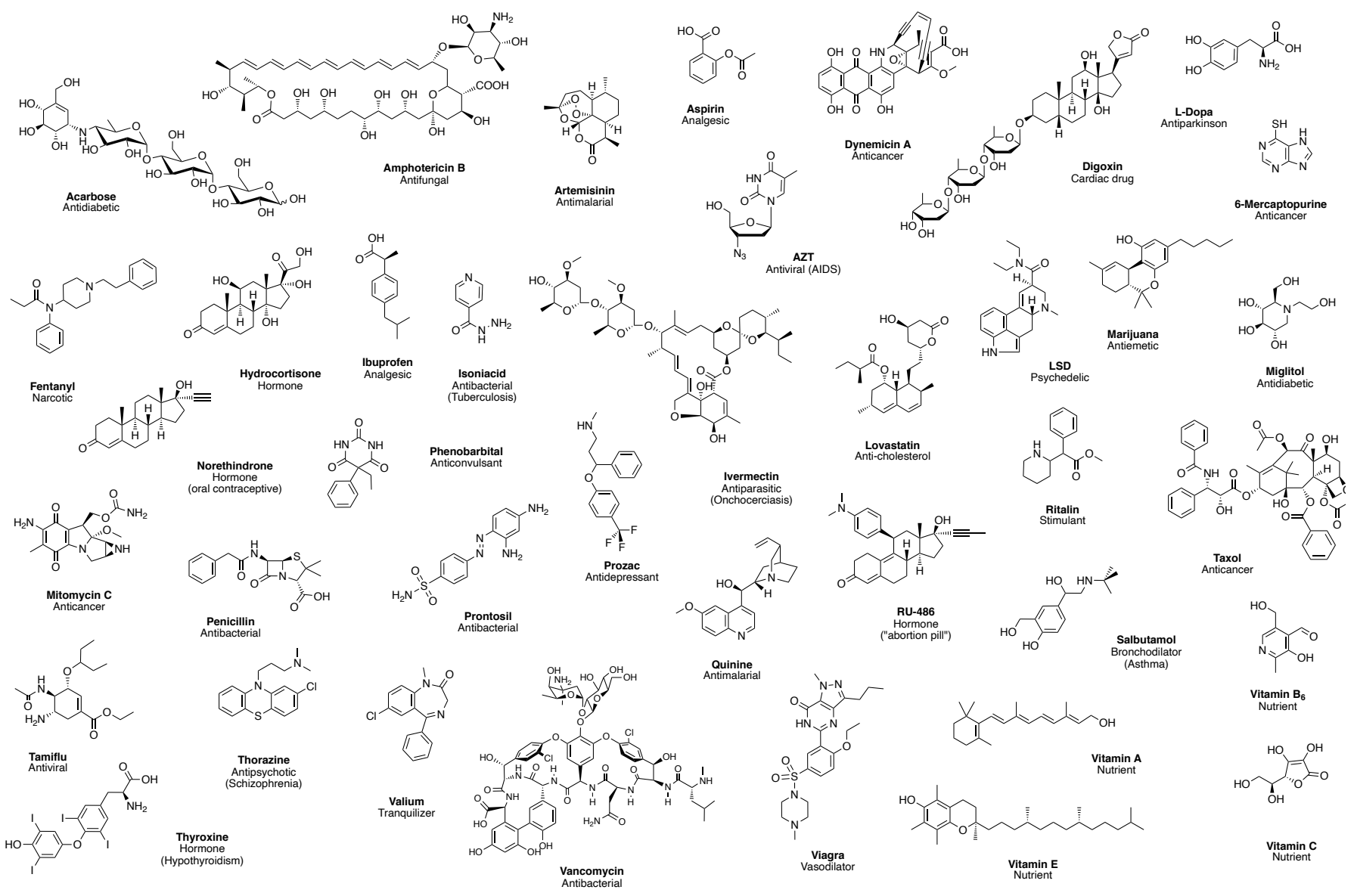

Fig. 3. Selected molecules that changed our world (with some exceptions): A collection of molecular masterpieces produced as 'relevance triggers' for medicine students not to memorize but to admire and to use, to work with, practicing functional groups, octet rule, stereochemistry, acidity, reactivity, and so on.

red, ${ }^{[8,9]}$ adamantane (vide infra $\left.{ }^{[10-13]}\right), \alpha$-thujone, the active molecule in absinth, as a local contribution to the culture around van Gogh (synthesized in my Department of Organic Chemistry ${ }^{[14,15]}$ ), Hoffman's LSD, clearly more potent, marking the sixties, ${ }^{[16]}$ and so on.

The real introduction then opens with the central question: Why organic chemistry for medical students? (Fig. 2). I start opening Le Temps, ${ }^{[2]}$ keyword medicine, topic antibiotic resistance, vancomycin, how does it work? A question relevant for medicine, no doubt. The journalist finds the answer in organic chemistry, the experts on the molecular level: Vancomycin recognizes D-Ala-D-Ala, bacteria resist by changing one functional group into another, an amide into an ester, that is replacing just one atom, a nitrogen by an oxygen ${ }^{[17,18]}$ (Fig. 2). To understand vancomycin resistance, we conclude that we have to understand the nature of molecules, functional groups, and even atoms. The structure of vancomycin is then used in the following to introduce the drawing of molecules (tetrahedral, trigonal carbons), functional groups (with lactams as highlight, immediately repeated to introduce basics of peptide chemistry), and recap of the essentials of atoms needed in organic chemistry.

Vancomycin is arguably one of the molecules that changed our world (to the better). [19] Some of these privileged scaffolds or ' $m o-$ lecular masterpieces' are summarized in a separate page, inspired by a special issue of Chem. Eng. News, ${ }^{[19]}$ with Leo Sternbach rotavaping valium on the cover, ${ }^{[20]}$ completed to cover most examples in the course, made for students not to memorize but to admire structural beauty in organic chemistry - and to work with, practice lessons learned (identify functional groups, stereochemistry, acidity, conformers, ring tension, mesomers, tautomers, conjugation, aromaticity, reactivity, and modes of action as far as possible, Fig. 3).

The second molecule from this list brought up already in the introduction to justify the learning of reaction mechanisms is Tamiflu. Unlike vancomycin, Tamiflu is a synthetic molecule (rather than a natural product), sculpted by chemists (rather than medical doctors), to some extent another modern Swiss masterpiece, an antiviral which made waves in the news in the early

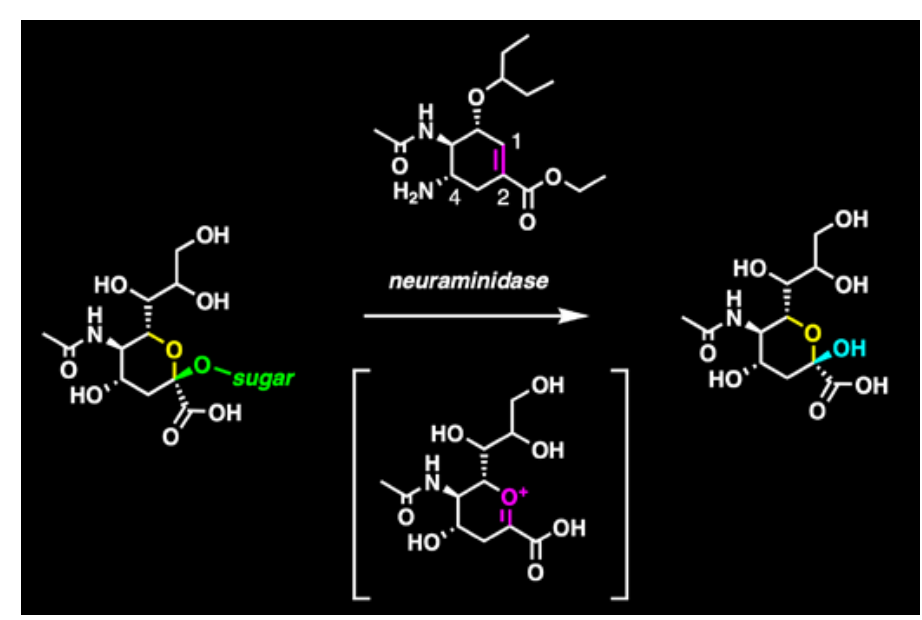

Fig. 4. The teaching of reaction mechanisms to first year medicine students is justified already in the introduction with Tamiflu. The chemistry is explained much later in the chapter on carbonyl group reactivity, and all involved motifs used throughout the course. Adapted screenshot from course material. 
2000s. ${ }^{[21]}$ The opening question for the students is how to explain to a customer, a patient or a journalist, how Tamiflu works. The answer is that Tamiflu is the stable analog of the decisive reactive intermediate and the adjoining transition state of the reaction catalyzed by an enzyme of the virus, namely the transformation of an acetal into a hemiacetal (Fig. 4). With catalysts recognizing transition states rather than substrates, Tamiflu thus inhibits this enzyme. While details of this reaction come much later in the course, the message in the introduction is that one good reason to learn organic chemistry reaction mechanisms is to understand how drugs work, or even how to create new ones. The same justification is repeated later on with miglitol, acarbose ${ }^{[22]}$ and, most useful, with lovastatin ${ }^{[23]}$ (see below). Tamiflu and lovastatin return throughout the course as leitmotifs to practice functional groups, stereochemistry $(R / S, E / Z)$, acidity, and, of course, reaction mechanisms and hybridization. In a right/wrong (+/-) multiple choice exam question, this can look like: A) At pH 7, the charge of Tamiflu is +1 ; B) Tamiflu contains an ester, a lactam and an imine; $\mathrm{C}$ ) the configuration of the $\mathrm{C}=\mathrm{C}$ double bond in Tamiflu is $Z$, the configuration of $\mathrm{C}(4)$ is $R$; D), if desired, the hybridization of $\mathrm{C}(1)$ and $\mathrm{C}(2)$ is $s p^{2}$ and important for antiviral activity; and so on.

Relevance-triggered teaching of the first, more structural part of the course uses mainly lipids, steroids and sugars as leitmotifs. Lipids serve well to 'trigger' the octet rule (extensions to charges, third period), conformers (anti, staggered, Newman projection), alkanes $(E / Z)$, and physical properties (bilayer formation, repeated with ion channels formed by amphotericin B (Fig. 2)). The original pill, norethindrone, works well as 'ethnochemical' Djerassi[24] entry to steroids to trigger all cycloalkane chemistry (chair/envelope, axial/equatorial, cis/trans fusion, Fig. 5). Adamantane can be added as a 'Swiss' 3D challenge, also to point out how adding one single atom can lead from 'useless' fundamental science ${ }^{[10,11]}$ to antivirals ${ }^{[12,13]}$ (Fig. 1).
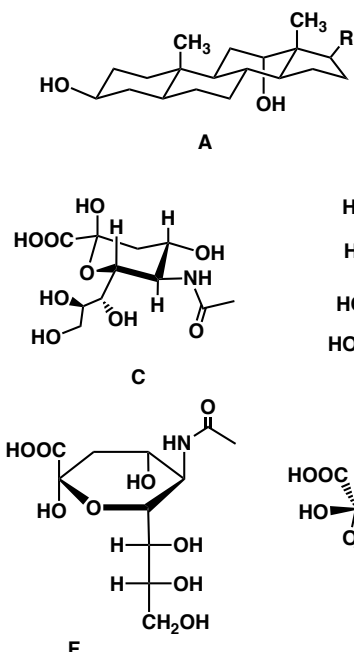

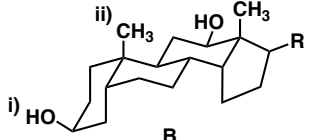

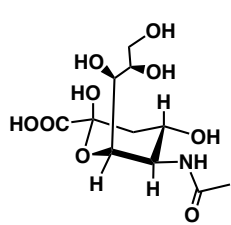

D
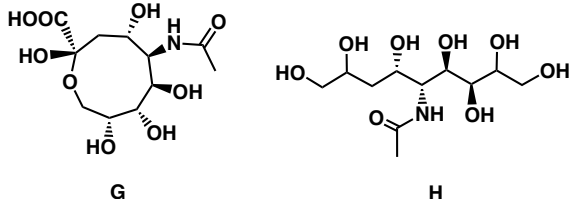

H

Fig. 5. Steroids and sugars introduced first to justify ('relevance-trigger') the teaching of cycloalkanes and beyond, here selected questions for digoxin (Fig. 3, A/B right/wrong, i) substituent equatorial?, ii) how many 1,3-diaxial interactions?), and sialic acid (Fig. 4) to combine structural understanding with reactivity (Haworth/Fischer, stereochemistry, hemiacetal equilibria, anomers, redox).

The reactivity part starts with and focuses heavily on carbonyl chemistry, from aldehydes and ketones (hydrate, hemiacetals, acetals, imines) to carboxylic acid derivatives (amides, esters) and $\mathrm{C}-\mathrm{C}$ bond formation (aldol, Claisen, Fig. 6). Preceded by descriptive redox chemistry from alcohols to acids, reaction mechanisms are introduced with nucleophilic addition to carbonyls. First with water, later on alcohols (sugars), amines (peptides), hydrides (lo-
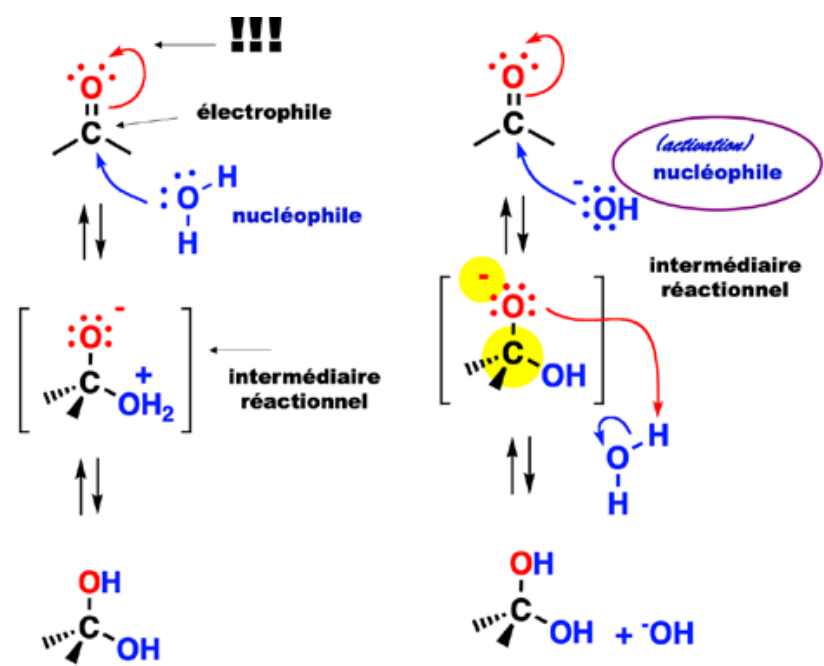

Fig. 6. Reactions are introduced with carbonyl chemistry, addition to aldehydes and ketones first, including base and acid catalysis from the beginning, proceeding quickly to the reaction mechanisms that explain how Tamiflu works (Fig. 4). Adapted screenshot from course material.

A
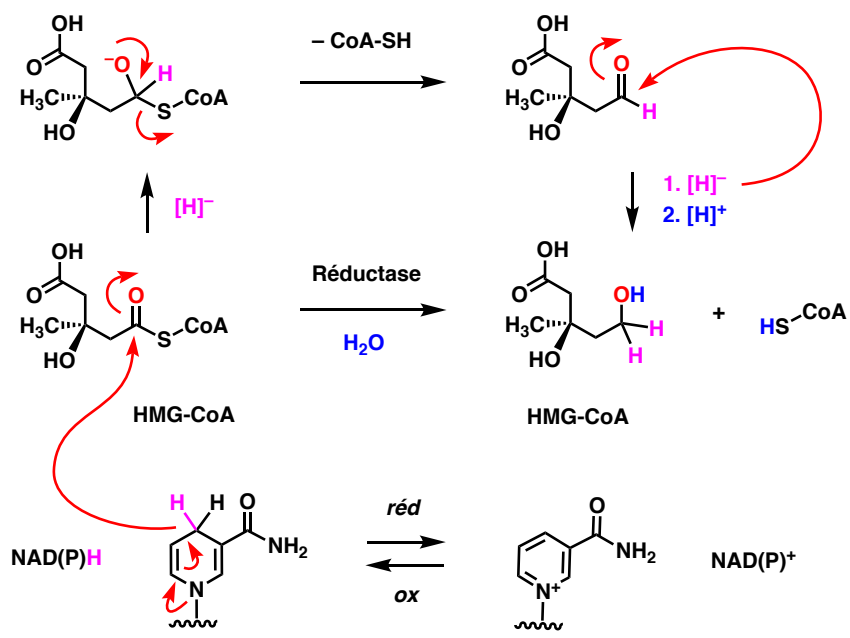

B
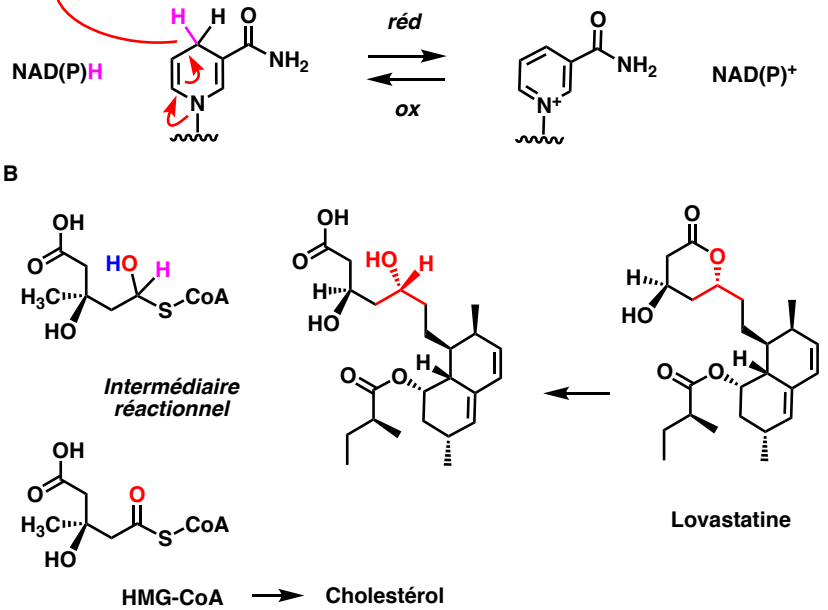<smiles>CCCCCCCCCC[n+]1cccc(C(N)=O)c1</smiles>

NAD(P) ${ }^{+}$

Lovastatine

Fig. 7. Lovastatin as another leitmotif to justify the emphasis on carbonyl chemistry, with $(A)$ the understanding of reaction mechanisms leading to (B) the understanding of how the drug works: Lactone hydrolysis affords the secondary alcohol that reproduces the tetrahedral carbon of the reactive intermediates of thioester reduction by hydride addition, thiolate elimination, and another hydride addition to the aldehyde intermediate. Adapted screenshot from course material.

vastatin), carbons (aldol, Claisen). The concepts of base and acid catalysis are introduced right at the beginning (Fig. 6).

Moving from water to alcohols, reaction mechanisms can be practiced first in the context of Tamiflu[21,22] and miglitol.[22] Now it can be understood that the antiviral acts as stable analog of the central reactive oxonium intermediate of acetal hydroly- 
sis because the planarity from $s p^{2}$ hybridization is reproduced in stable form, i.e. a carbon-carbon double bond (Fig. 4). This $s p^{2}$ topology is missing in substrate and product and thus is thought to help the enzyme to recognize and stabilize the transition state, i.e. catalyze the reaction. In the following, sialic acid (Tamiflu), glucose (the anti-diabetic miglitol, acarbose ${ }^{[22]}$ ) and other sugars are convincing 'relevance triggers' to practice carbonyl reactivity in combination with structural basics (hemi-/acetals, anomers, Fischer/Haworth, axial/equatorial, redox, Fig. 5).

Lovastatin and the related statin family were identified as a particularly useful 'relevance trigger' (Fig. 7). ${ }^{[19,23]}$ They nicely complement the Tamiflu example by focusing on thioester reduction with hydride as the nucleophile adding to the carbonyl. Lovastatin can be considered as stable 'transition-state analog' inhibitor of the reductase, reproducing the tetrahedral carbon of the reactive intermediate and adjoining transitions states in the form of a secondary alcohol.

However, this is not all. Lovastatin is activated by lactone hydrolysis, another reaction that is covered in the course as ester hydrolysis and the reverse Fischer esterification in full mechanistic detail. Finally, lovastatin inhibits cholesterol biosynthesis. Full understanding of cholesterol biosynthesis and continuing steroidogenesis until cortisone ${ }^{[25]}$ is an explicit expectation from organic chemistry for first year students in medicine that cannot be met within the given time constraints. However, step-by-step cholesterol biosynthesis is provided as a handout and examples are taken from it whenever possible. There are many wonderful examples included, from the introductory Claisen and aldol condensations over carbocation-alkane chemistry, epoxide ring tension and leaving groups in the cascade cyclization to the final redox chemistry surrounding hormones like testosterone or cortisone, another Swiss masterpiece. ${ }^{[25]}$ The oxidation of dehydroepiandrosterone to androstenedione is shown as an example for the many more hidden 'relevance triggers' that can be found (Fig. 8). The oxidation of a secondary alcohol to a ketone simply illustrates the basics covered in the course. The coinciding double-bond migration, however, provides a more original expression of enol chemistry introduced in the context of aldol and Claisen condensations, and repeats double-bond conjugation covered earlier in the structural part of the course. ${ }^{[26]}$

The unusual structure of the course might be best appreciated by considering what is missing. Nomenclature is completely removed (except for stereochemical designations cis/trans, E/Z,

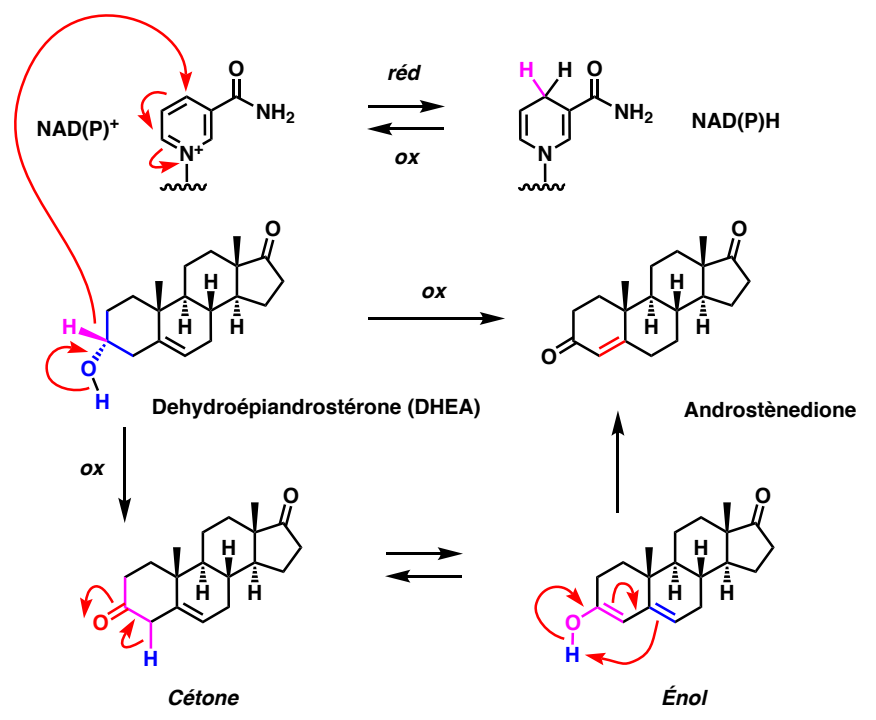

Fig. 8. Steroidogenesis to justify the emphasis on carbonyl chemistry. The double-bond migration upon standard alcohol oxidation can be understood with the basics of enol tautomers and conjugation.
$R / S$ and also $P / M$, axial chirality important for peptide and DNA helices). Reactions with alkynes and aromatics are removed (electrophilic/nucleophilic aromatic substitutions, etc.), alkenes cut to a minimum. Covered less in depth but certainly present near the end are $\mathrm{S}_{\mathrm{N}} 2$ reactions (Why does smoking cause cancer? No, its not the nicotine. Or how do we produce an adrenaline rush?). Same for $\mathrm{S}_{\mathrm{N}} 1$ reactions (carbocations, cholesterol biosynthesis).

What is emphasized instead is 'relevance-triggered teaching', every topic covered is approved and justified first, before the introduction of the basic principles concerned. Vancomycin resistance, Tamiflu, lovastatin, and cholesterol biosynthesis are used as recurrent themes. These 'relevance triggers' serve to emphasize saturated carbo- and heterocycles in the structural part and carbonyl chemistry in the reactivity part of the course.

To chose a few, not further special technical comments: We receive $26 \mathrm{~h}$ for teaching and $18 \mathrm{~h}$ for exercise sessions. If possible, teaching is always done with a co-teacher to depersonalize organic chemistry. Exercise sessions are done in groups by eight teaching assistants. With the largest room available limited to 400 students, the course is shown also in a second room without a teacher, can be followed from home by live streaming, and recordings are available on the Moodle-site of the course until the exam. All basic topics covered are referred to the respective page in the short version of the French translation of the McMurry-Simanek textbook $^{[1]}$ to guide additional reading, important specially for students that come with little knowledge of organic chemistry. Specific summaries are added for reactions, $\mathrm{p} K_{\mathrm{a}}$ 's, amino acids, carbohydrates, steroidogenesis. On an online forum, questions from students are continuously answered. Online office hours were added during this year's confinement. The overall experience during confinement was that online teaching is feasible but so much passion and empathy are lost: Nothing can replace the live experience, the direct contact between students and teachers, throughout the course, particularly in the exercise sessions.

In summary, 'relevance-triggered teaching' of organic chemistry under Geneva conditions has passed the test of time without serious problems and with mostly encouraging feedback from students. Reminiscent at least of aspects of 'case-study' teaching, ${ }^{[27,28]}$ the essence of 'relevance-triggered teaching' is to develop a solid 'medical-school-approved' justification for every topic covered, to deliver this justification first, not last, and then use it throughout the explanations as recurrent themes for illustration, application, in exercises and in exam questions. The resulting course is far from perfect. Writing this article, I realize again how much could be improved, ultimately, perhaps, developed into a textbook.

It has always been an honor and a great pleasure to teach organic chemistry to first year medical students in Geneva in this form. I thank the many colleagues and students from the Medical School for stimulating discussions, and I am deeply grateful to Damien Jeannerat, Fabien Cougnon and all the superb assistants who contributed so much over the years to teach organic chemistry at the Medical School of the University of Geneva, and to improve the course and, hopefully, the perception of chemistry by the 'grand public'.

Received: October 24, 2020

[1] J. McMurry, E. Simaneck, 'Chimie Organique. Les grands principes'. $2^{\text {nd }}$ Edn., Dunod, Paris, 2007.

[2] https://www.letemps.ch/.

[3] http://institutions.ville-geneve.ch/fr/mah/expositions-evenements/expositions/alberto-giacometti/. Accessed 18.9.2020.

[4] L. Pray, Nat. Educ. 2008, 1, 37.

[5] 'Drugs That Fight Cancer', TIME, May 28, 2001.

[6] L. Ruzicka, Nobel Lecture, Dec.12, 1945, 'Multimembered Rings, Higher Terpene Compounds and Male Sex Hormones', https://www.nobelprize.org/prizes/chemistry/1939/ruzicka/lecture/. Accessed 24.10.20.

[7] L. Ruzicka, Helv. Chim. Acta 1926, 9, 715. 
[8] Z. Hao, A. Iqbal, Chem. Soc. Rev. 1997, 26, 203.

[9] M. Grzybowski, D. T. Gryko, Adv. Opt. Mater. 2015, 3, 280.

[10] V. Prelog, R. Seiwerth, Ber. Dtsch. Chem. Ges. 1941, 74, 1644.

[11] V. Prelog, Nobel Lecture, Dec. 12, 1975, 'Chirality in Chemistry', https://www.nobelprize.org/prizes/chemistry/1975/prelog/lecture/. Accessed 24.10.20.

[12] A. L. Stouffer, R. Acharya, D. Salom, A. S. Levine, L. Di Costanzo, C. S. Soto, V. Tereshko, V. Nanda, S. Stayrook, W. F. DeGrado, Nature 2008, 451, 596.

[13] J. R. Schnell, J. J. Chou, Nature 2008, 451, 591.

[14] W. Oppolzer, A. Pimm, B. Stammen, W. E. Hume, Helv. Chim. Acta 1997, 80,623 .

[15] I. Thamm, J. Richers, M. Rychlik, K. Tiefenbacher, Chem. Commun. 2016, 52,11701 .

[16] N. S. Finney, J. S. Siegel, Chimia 2008, 62, 444.

[17] T. D. H. Bugg, G. D. Wright, S. Dutka-Malen, M. Arthur, P. Courvalin, C. T. Walsh, Biochemistry 1991, 30, 10408.

[18] J. Xie, J. G. Pierce, R. C. James, A. Okano, D. L. Boger, J. Am. Chem. Soc. 2011, 133, 13946.

[19] 'A Look at Drugs that Changed our World', Special Issue, Chem. Eng. News 2005, June 20.

[20] 'Good Chemistry: The Life and Legacy of Valium Inventor Leo Sternbach', McGraw-Hill, 2004.

[21] M. Karpf, R. Trussardi, Angew. Chem. Int. Ed. 2009, 48, 5760.
[22] T. M. Gloster, G. J. Davies, Org. Biomol. Chem. 2010, 8, 305.

[23] V. F. Roche, Amer. J. Pharm. Educ. 2005, 69, 546.

[24] C. Djerassi, 'Steroids Made it Possible', 1990, American Chemical Society, https://doi.org/10.1002/oms.1210271213

[25] T. Reichstein, Nobel Lecture, Dec. 11, 1950, 'Chemistry of the Adrenal Cortex Hormones',

https://www.nobelprize.org/prizes/medicine/1950/reichstein/lecture/. Accessed 24.10.20.

[26] S. D. Fried, S. Bagchi, S. G. Boxer, Science 2014, 346, 1510.

[27] C. F. Herreid, J. Col. Sci. Teach. 1994, 23, 221.

[28] K. M. Bonney, J. Microbiol. Biol. Educ. 2015, 16, 21.

\section{License and Terms}

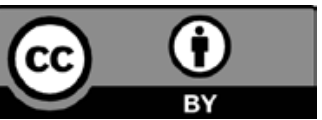

This is an Open Access article under the terms of the Creative Commons Attribution License CC BY 4.0. The material may not be used for commercial purposes.

The license is subject to the CHIMIA terms and conditions: (http:// chimia.ch/component/sppagebuilder/?view=page \&id=12).

The definitive version of this article is the electronic one that can be found at https://doi.org/10.2533/chimia.2021.27 